\title{
Enhanced Corrosion Protection of Polypyrrole Coatings on Carbon Steel via Electrodeposition
}

\author{
Bailong Liu ${ }^{1,2}$, Zhaohui Zhang ${ }^{1,2, *}$, Jiangkai Wan ${ }^{1}$, Shifeng Liu ${ }^{1,2}$ \\ ${ }^{1}$ School of Metallurgical Engineering, Xi'an University of Architecture and Technology, Xi'an \\ 710055, P R China \\ ${ }^{2}$ Shaanxi Province Metallurgical Engineering and Technology Research Centre, Xi'an University of \\ Architecture and Technology, Xi'an 710055, P R China \\ *E-mail: 249749434@qq.com
}

doi: $10.20964 / 2017.02 .20$

Received: 7 November 2016 / Accepted: 12 December 2016 / Published: 30 December 2016

\begin{abstract}
Herein, we reported the successful electrodeposition of polypyrrole (PPy) composite coatings on the carbon steel through cyclic voltammetry in the oxalic acid as the electrolytes, where no phosphotungstate (PW12) present as the dopant. To determine the erosion performance of the samples after coating, element analysis, scanning electron microscopy (SEM) and electrochemical techniques were employed in this paper. According to the corrosion-resistant capacity of the coating, it was demonstrated the coating composed of PPy composite was efficient in protection of iron compared to pure PPy. Furthermore, the corrosion capacity was also enhanced at the open circuit as well as the potentials when the pitting attack took place on the bare substrate.
\end{abstract}

Keywords: Polypyrrole; Electrodeposition; Corrosion; Coating; Phosphotungstate

\section{FULL TEXT}

(C) 2017 The Authors. Published by ESG (www.electrochemsci.org). This article is an open access article distributed under the terms and conditions of the Creative Commons Attribution license (http://creativecommons.org/licenses/by/4.0/). 